\title{
Accuracy of Fetal Weight Estimation by Ultrasonographic Evaluation in a Northeastern Region of India
}

\author{
Ranjumoni Konwar, ${ }^{1}$ Bharati Basumatary, ${ }^{1}$ Malamoni Dutta, ${ }^{2}$ and Putul Mahanta $\mathbb{D}^{3}$ \\ ${ }^{1}$ Radiology, Fakhruddin Ali Ahmed Medical College and Hospital, Barpeta 781301, Assam, India \\ ${ }^{2}$ Anatomy, Assam Medical College and Hospital, Dibrugarh 786002, Assam, India \\ ${ }^{3}$ Forensic Medicine and Toxicology, Assam Medical College and Hospital, Dibrugarh 786002, Assam, India \\ Correspondence should be addressed to Putul Mahanta; drpmahanta@gmail.com
}

Received 15 September 2021; Revised 21 November 2021; Accepted 11 December 2021; Published 20 December 2021

Academic Editor: Nicholas Dunne

Copyright ( 92021 Ranjumoni Konwar et al. This is an open access article distributed under the Creative Commons Attribution License, which permits unrestricted use, distribution, and reproduction in any medium, provided the original work is properly cited.

\begin{abstract}
Background and Objectives. Fetal weight evaluation in utero is a significant component in obstetric practices. The present study aims to estimate the fetal weight (EFW) by evaluating two available formulas using ultrasound parameters and comparing them with actual birth weight (ABW) after delivery. The accuracy and efficacy of both EFW formulas in detecting intrauterine growth retardation (IUGR) and macrosomia were also compared in our local sample of the population. Methods. The cross-sectional study included 100 pregnant women aged 20-45 years from the Kamrup district admitted to Guwahati Medical College and Hospital, Guwahati, Assam. The data were analyzed using Microsoft Excel and SPSS version 16. The EFW at term was calculated using Shepard's formula and Hadlock's formula. Differences in means are compared using the one-way ANOVA or Kruskal-Wallis test and paired $t$-test. The accuracy of the two procedures was evaluated using mean absolute error (MAE) and mean absolute percentage error (MAPE). A $p$ value $<0.05$ was considered significant. Results. The present study included 100 pregnant women aged 21-38 years with term or postterm pregnancies subjected to ultrasonographic evaluation within 72 hours of delivery. The mean ( \pm s.d.) EFW by Shepard's formula was $2716.05( \pm 332.38) \mathrm{g}$ and Hadlock's formula was $2740.44( \pm 353.23) \mathrm{g}$, respectively. For Hadlock's formula, MAE \pm s.d. was found to be higher (overall $84.59 \pm 76.54$ ) specifically in the weight category less than $2500(106.42 \pm 88.11)$ as compared to Shepard's (overall MAE \pm s.d $=79.86 \pm 64.78$, and among ABW $<2500 \mathrm{~g}$, MAE \pm s.d $=65.04 \pm 61.02$ ). The overall MAPE of Hadlock's formula was $3.14 \%$ and that for Shepard's formula was $2.91 \%$, and the difference was not statistically significant. Both Shepard's formula and Hadlock's formula had a sensitivity of $92.85 \%$ in detecting IUGR, but Hadlock's method had higher specificity (66\%), higher PPV (86.67\%), and higher NPV (80\%). Conclusion. The ultrasonographic evaluation of fetal weight helps predict fetal birth weight precisely and can influence obstetric management decisions concerning timing and route of delivery, thus reducing perinatal morbidity and mortality.
\end{abstract}

\section{Introduction}

Estimation of fetal weight in utero had formed a significant component in obstetrical practices, ever since the inception of ultrasonography pioneered by Dr. Ian Donald in 1958 [1]. Fetal weight estimation plays a vital role in many obstetrical decisions regarding intrauterine growth monitoring, delivery, as well as determining high-risk pregnancies $[2,3]$.

Fetal weight is considered an independent risk factor of high perinatal morbidity and mortality. Both low and high fetal weight at delivery may lead to complications in labor and delivery to both the child and mother [2-4].

The perinatal complications associated with low birth weight are fetal prematurity and IUGR, a growth disorder of the fetus defined as a fetal weight below the $10^{\text {th }}$ percentile for age, which is a significant risk factor of neonatal morbidity and mortality [5].

Macrosomia is defined as a fetal weight above $4000 \mathrm{~g}$ or a birth weight above the $90^{\text {th }}$ percentile for gestational age. Inaccuracy in the estimation of fetal weight may also 
increase the risk in management and during delivery, specifically in suspected macrosomia [6-9].

Before the availability of ultrasound, conventional methods such as palpation of the maternal circumference and measurement of the maternal abdominal circumference and uterine height were used to estimate fetal weights. Though the traditional methods are easy to use, several maternal factors may affect assessment abilities, such as myomas, obesity, multiple gestations, and the amount of amniotic fluid. Hence, the assessments by the conventional methods may be inaccurate sometimes $[2,10]$.

Modern sonographic predictions are based on regression algorithms using various combinations of fetal parameters such as head circumference (HC), the length going around the baby's head, abdominal circumference (AC), the length going around the baby's belly, biparietal diameter (BPD), the diameter of the baby's head, and femur length (FL), the length of the femur in the baby's leg. Earlier, many authors suggested various formulas for fetal weight estimation using single fetal parameters [11-13]. Subsequently, utilization of two parameters for fetal weight measurement, including BPD and AC, was introduced by few authors since 1970s [14-16]. Hadlock et al. [17] proposed an improved formula for fetal weight estimation using $\mathrm{HC}, \mathrm{AC}, \mathrm{FL}$, and BPD. Various combinations of ultrasonically derived measurements were tried and tested by many authors with complex mathematical expressions for estimating fetal weights [18].

The present study aims to determine the usefulness and accuracy of estimating fetal weight at term pregnancies using sonographic measurements by two available formulas: Shepard's formula and Hadlock's formula, with particular reference to suspected IUGR macrosomia in a northeastern city of India.

\section{Materials and Methods}

A cross-sectional study includes 100 pregnant women with term and postterm pregnancies from the Kamrup district of Assam admitted to Guwahati Medical College and Hospital aged 20-45 years. Participants with a gestational age of 37-40 weeks and who were expected to deliver less than 72 hours of sonographic examination were included. Viable fetuses of all weight categories were included concerning suspected IUGR babies. Suspected fetuses of having brachycephaly (cephalic index $>85$ ) and dolichocephaly $(\mathrm{CI}<75)$ were excluded.

The sample size was determined using the Windows version (WINPEPI version 11.65) of the PEPI suite of programs for epidemiologists. The sample size of 100 is sufficient to estimate a difference in mean weight of $100 \mathrm{~g}$ with a $5 \%$ level of significance and $80 \%$ power considering standard deviation of EFW by Hadlock's formula as $420 \mathrm{~g}$ and by Shepard's formula as $0.538 \mathrm{~g}$ and correlation coefficient of 0.77 [19].

The sonographic evaluation was performed using Siemens Sonoline 2, a real-time grayscale scanner using a 3.5 MHz transducer. A linear array probe was preferably used for the examination. Fetal weight estimation was derived from Shepard's formula $=\mathrm{BPD} / \mathrm{AC}$ and Hadlock's formula $=\mathrm{AC} / \mathrm{FL} . \mathrm{BPD}$ is measured at the widest portion of the skull from the outer edge of the proximal skull table to the inner edge of the distal skull table perpendicular to the middle echo complex using electronic callipers. The AC was measured in the transverse plane perpendicular to the long axis of the fetal aorta or spine at the level of the portoumbilical vein complex within the liver. FL is measured as the linear distance between two calcified diaphyseal ends of the femur, which corresponds anatomically from the greater trochanter of the femur to the distal metaphysis. All the sonographic measurements were recorded in millimetres (mm). Estimation of fetal weights was done by referring to established charts derived from two published formulas, i.e., Shepard's formula that used the combination of BPD and $\mathrm{AC}$ is represented as

$$
\text { EFW: } \begin{aligned}
\log _{10}(\mathrm{BW})= & -1.7492+0.166(\mathrm{BPD})+0.046(\mathrm{AC}) \\
& -2.646(\mathrm{AC}+\mathrm{BPD}) / 1000
\end{aligned}
$$

Hadlock's formula that used the combination of AC and FL is represented as

$$
\begin{aligned}
\mathrm{EFW}: \log _{10}(\mathrm{BW})= & 1.3598+0.051(\mathrm{AC})+0.1844(\mathrm{FL}) \\
& -0.0037(\mathrm{AC} \times \mathrm{FL}) .
\end{aligned}
$$

Each study participant was thoroughly assessed before ultrasound evaluation, including patient history, clinical examination, and routine laboratory examination.

2.1. Statistical Analysis. The paired $t$-test and one-way ANOVA or Kruskal-Wallis test were performed to test the difference in means. Correlation analysis was done using scatter plots. The accuracy of the sonographic estimation methods was determined by computing the mean absolute error as $\mathrm{MAE}=$ mean $|\mathrm{EFW}-\mathrm{ABW}|$ and mean absolute percentage error as $\mathrm{MAPE}=$ mean $\mid(\mathrm{EFW}-\mathrm{ABW}$ $(\mathrm{ABW}) \times 100) \mid$. The accuracy of the formulas in detecting IUGR was assessed using sensitivity analysis. The data were analyzed using Microsoft Excel and SPSS version 16. A $p$ value $<0.05$ was considered significant. Prior collection of the ethical data approval was taken from the Ethics Committee of Guwahati Medical College, Guwahati, Assam, and the participant's informed consent.

\section{Results}

The study participants' age range was 21-38 years. Most participants (59\%) were from urban areas and belonged to the middle or lower class economic background (75\%). Also, $20 \%$ had suspected IUGR.

Among the 100 pregnancies, 30\% each were primigravida and primipara and $40 \%$ were multiparous women. The majority, $62 \%$, deliveries were spontaneous, and $31 \%$ were by the lower segment cesarian section (LSCS). The mean and standard deviation (s.d.) ABW of the newborns was $2740.35 \pm 354.19 \mathrm{gm}$. Among the newborns, $48 \%$ were 
male and 52\% were females. Eighty-four babies had weight appropriate for gestational age (AGA), 14 were small for gestational age (SGA), and only 2 were large for gestational age (LGA). Mean maternal weight was found significantly different ( $p$ value $<0.01$ ) among the AGA, SGA, and LGA groups (Table 1).

The mean ( \pm s.d.) EFW by Hadlock's formula was found to be 2740.44 (353.23), which was close to the mean ( \pm s.d.) ABW of 2740.35 (354.19), and the paired $t$-test revealed no significant difference between mean ABW and mean EFW by Hadlock's formula. But in our present study, the mean EFW by Shepard's formula was found to be significantly different ( $p$ value 0.017 ) from mean ABW, as given in Table 2.

The EFWs by Hadlock's formula plotted against ABW of the newborns reveal a significant positive correlation $(r=0.948, p$ value $<0.01)$, as shown in Figure 1. Similarly, as shown in Figure 2, the EFWs by Shepard's formula plotted against $\mathrm{ABW}$ show a linear relationship with a significant positive correlation $(r=0.96, p$ value $<0.01)$.

Both formulas estimated an equal number of cases in the weight category 2501-3000 g (67\%). In the 2001-2500 g weight category, Shepard's formula could assess more cases than Hadlock's formula. Also, Shepard's formula predicted the exact number of patients in more than $3500 \mathrm{~g}$ weight groups. Both the procedures predicted 2 macrosomic birth, as given in Table 3 .

The MAE for Hadlock's formula was higher than that for Shepard's formula. MAE for Hadlock's procedure was highest in the below $2500 \mathrm{~g}$ ABW weight group with MAPE of almost $4.6 \%$. The overall MAPE of Hadlock's formula was $3.14 \%$ and that for Shepard's formula was $2.91 \%$. The difference was not statistically significant, as given in Table 4 .

3.1. Sonological Detection of IUGR Cases. Both the formulas correctly predicted 13 IUGR cases out of a total of 15 proved IUGR cases and had $92.8 \%$ sensitivity in detecting IUGR; however, Shepard's formula had a lower specificity as compared to Hadlock's formula, as given in Table 5.

3.2. Sonological Detection of Macrosomia Cases. In our study, two patients were estimated by both formulas. Both the cases were proved to be macrosomia by $\mathrm{ABW}$.

\section{Discussion}

Fetal weight estimation at term may reduce the risk of perinatal mortality and morbidity by predicting IUGR and macrosomia before birth. As fetal weight cannot be measured directly, fetal and maternal anatomical characteristics (BMI, sex, and gestational age) are being used over the years $[3,20]$.

The age range of the patients was $21-38$ years. The present study reveals that out of 14 SGA babies, mothers of 6 had parity 0 . Many studies have suggested nulliparity as a factor affecting low birth weight [21-23]. Also, mean maternal weight was significantly different among AGA, SGA, and LGA groups ( $p$ value $<0.01$ ) with a proportional increase in $\mathrm{ABW}$ with maternal weight implying maternal weight gain as a significant factor affecting the weight gain of the baby inside the womb [24-26].

The mean ABW in the present study was 2740.35 (354.19) $\mathrm{g}$ which is concordant with many other studies conducted in different parts of India [27-29]. Mean EFW by Shepard's formula was significantly different from mean $\mathrm{ABW}$, indicating a fair underestimation of $\mathrm{ABW}$ by Shepard's formula [30, 31]. EFW estimated from both the procedures yielded an incredibly positive correlation with ABW of more than 0.9 coincident with other studies $[3,32,33]$. For Hadlock's formula, MAE was higher, specifically in the weight category less than $2500 \mathrm{~g}$ compared to Shepard's. MAE in our study is relatively lower than several other studies $[3,34,35]$; however, the results suggest that the accuracies of EFW formulas changed with different weight categories [34]. The overall MAPE of Hadlock's formula was $3.14 \%$ and that for Shepard's formula was $2.91 \%$, and the difference was not statistically significant. The MAPE in our study was lower than other studies [36, 37], suggesting the formula's usefulness in estimating the fetal weights at term in our local population.

Both the formulas had a sensitivity of $92.85 \%$ in detecting IUGR, but Hadlock's method had higher specificity (66\%). Various studies recommended different Hadlock's formulas as efficient in predicting IUGR with high sensitivity and specificity $[38,39]$. While in contrast to our findings, Shepard's formula was reported to have very low sensitivity and specificity in detecting IUGR in a review [40].

In the current study, 20 cases were suspected IUGR, out of which 15 were proved IUGR cases. Both the formulas correctly predicted 13 IUGR cases. There were 8 mothers diagnosed with pregnancy-induced hypertension, 2 of which have been associated with IUGR babies. Studies have identified hypertensive disorder in mothers as one of the most typical causes of IUGR due to placental insufficiency [41-43]. In the present study, we have also used the "lcm rule" to assess amniotic fluid status [44]. The criterion for oligohydramnios is the largest vertical fluid pocket to be less than $1 \mathrm{~cm}$. In the present study, 6 pregnant mothers were found to have less amniotic fluid, out of which 5 (38.46\% of proved IUGR) mothers have given birth to IUGR babies. Thus, the predictive accuracy of sonography in the assessment of oligohydramnios in IUGR of our study was 83\%, which is comparable to the observations of Manning et al. [44].

In the present study, there were two cases of proven macrosomia, out of which one was a known diabetic case while the other one was presenting as a breach with the inadequate pelvis. Both cases had undergone LSCS after sonographically they were diagnosed to have macrosomic fetuses. Also, in the present study, out of 6 cases of breech presentation, 5 cases had a fetal weight of greater than $3 \mathrm{~kg}$, who all had undergone LSCS. Thus, the sonographic prediction of fetal weight helped in timely intervention by LSCS in all these cases.

Although EFW by sonography is an infallible tool for modern obstetric practice, its accuracy may comprise intra and interobserver variability. Multiple measurements, 
TABLE 1: Sociodemographic profile of the participants.

\begin{tabular}{|c|c|c|c|c|c|c|c|}
\hline Characteristics & Mean (s.d.) & Median & Range & $\begin{array}{c}\text { Mean (s.d.) } \\
\text { SGA }(n=14)\end{array}$ & $\begin{array}{c}\text { Mean (s.d.) } \\
\text { AGA }(n=84)\end{array}$ & $\begin{array}{l}\text { Mean (s.d.) } \\
\text { LGA }(n=2)\end{array}$ & $\begin{array}{c}P \text { value, }, \mathrm{K}-\mathrm{W} \\
\text { test }^{\#}\end{array}$ \\
\hline Maternal age & $27.13(3.34)$ & 26.50 & $21-38$ & $26.43(2.34)$ & $27.30(3.49)$ & $25.00(1.41)$ & 0.44 \\
\hline Parity ${ }^{\# \#}$ & & 1.00 & $0-5$ & $0-3$ & $0-5$ & 2 & - \\
\hline Maternal weight & $52.89(3.49)$ & 52.00 & $48-64$ & $49.57(1.99)$ & $53.25(3.21)$ & $61.00(2.83)$ & $<0.01^{*}$ \\
\hline Gestational age at delivery & $39.64(1.42)$ & 40.00 & $37-49$ & $39.71(0.91)$ & $39.63(1.50)$ & $39.50(0.71)$ & 0.93 \\
\hline
\end{tabular}

${ }^{*} P$ value $<0.05$ significant. ${ }^{*} \mathrm{~K}-\mathrm{W}$ test, Kruskal-Wallis test for more than two means. ${ }^{* \#}$ Parity is represented as median and range. s.d., standard deviation; SGA, small for gestational age (SGA); AGA, appropriate for gestational age; LGA, large for gestational age.

TABLE 2: Comparison of mean ABW and mean EFWs by ultrasonography methods.

\begin{tabular}{lccccc}
\hline & $N$ & Mean (s.d.) & Minimum & Maximum & Paired $t$ \\
\hline ABW & 100 & $2740.35(354.19)$ & 2000 & 4200 & \\
EFW by Hadlock & 100 & $2740.44(353.23)$ & 1847 & 4145 & -0.008 \\
EFW by Shepard & 100 & $2716.05(332.38)$ & 2089 & 4050 & 0.994 \\
\hline
\end{tabular}

s.d., standard deviation; ABW, actual birth weight; EFW, estimated fetal weight.

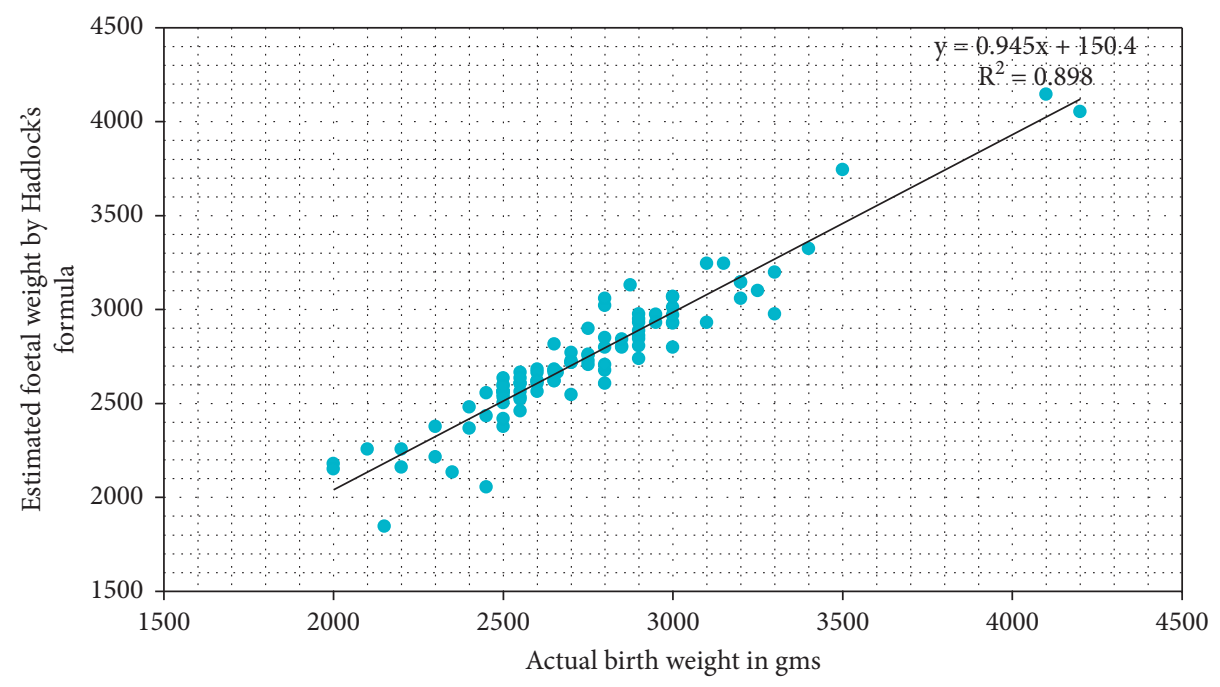

- Observed

— Linear (Observed)

Figure 1: Correlation between EFW (Hadlock's) and ABW.

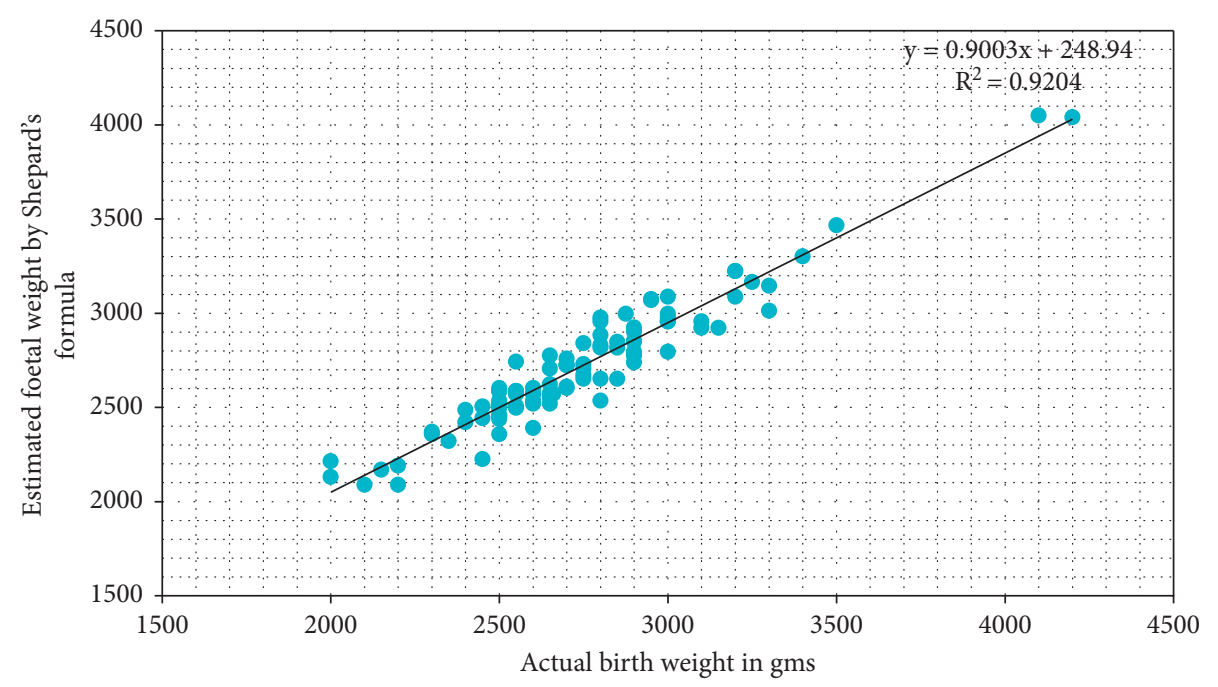

- Observed

- Linear (Observed)

Figure 2: Correlation between EFW (Shepard's) and ABW. 
TABLE 3: Distribution EFW and ABW among different weight categories.

\begin{tabular}{lccc}
\hline Weight category & $\begin{array}{c}\text { EFW by Hadlock's formula } \\
\text { Frequency (\%) }\end{array}$ & $\begin{array}{c}\text { EFW by Shepard's formula } \\
\text { Frequency (\%) }\end{array}$ & $\begin{array}{c}\text { ABW } \\
\text { Frequency (\%) }\end{array}$ \\
\hline $1500-2000$ & $1(1.0)$ & $0(-)$ & $2(2.0)$ \\
$2001-2500$ & $15(15.0)$ & $20(20.0)$ & $61(24.0)$ \\
$2501-3000$ & $67(67.0)$ & $67(67.0)$ & $11(11.0)$ \\
$3001-3500$ & $14(14.0)$ & $11(11.0)$ & $0(-)$ \\
$3501-4000$ & $1(1.0)$ & $0(-)$ & $2(2)$ \\
$4001-4500$ & $2(2.0)$ & $2(2.0)$ & $(2)$ \\
\hline
\end{tabular}

ABW, actual birth weight; EFW, estimated fetal weight.

TABLE 4: Accuracy of the different formulas for estimating EFW by the ultrasonic method.

\begin{tabular}{lccccc}
\hline \multicolumn{2}{c}{ ABW categories } & MAE, g (Hadlock's) & MAE, g (Shepard's) & MAPE, \% (Hadlock's) & MAPE, \% (Shepard's) \\
\hline$\leq 2500 \mathrm{~g}$ & $N=26$ & $106.42 \pm 88.11$ & $65.04 \pm 61.02$ & $4.59 \pm 3.89$ & $2.80 \pm 2.77$ \\
$2501-3500 \mathrm{~g}$ & $N=72$ & $76.39 \pm 71.52$ & $84.53 \pm 65.85$ & $2.64 \pm 2.38$ & $2.96 \pm 2.25$ \\
$>3500 \mathrm{~g}$ & $N=2$ & $96.00 \pm 72.12$ & $104.50 \pm 77.07$ & $2.30 \pm 1.70$ & $2.50 \pm 1.81$ \\
Total & $N=100$ & $84.59 \pm 76.54$ & $79.86 \pm 64.78$ & $3.14 \pm 2.94$ & $2.91 \pm 2.36$ \\
& & $P$ value for the paired $t$-test $=0.54$ & $P$ value for the paired $t$-test $=0.45$ \\
\hline
\end{tabular}

$\mathrm{ABW}$, actual birth weight; $N$, total sample size; MAE, mean absolute error; MAPE, mean absolute percentage error.

TABLE 5: Sonographic evaluation of IUGR.

\begin{tabular}{lcc}
\hline Diagnostics & $\begin{array}{c}\text { No. of } \\
\text { cases (\%) } \\
\text { by Shepard's }\end{array}$ & $\begin{array}{c}\text { No. of } \\
\text { patients (\%) } \\
\text { by Hadlock's }\end{array}$ \\
\hline Predicted IUGR & 16 & 15 \\
Proved IUGR & 13 & 13 \\
Missed IUGR & 1 & 1 \\
Wrongly diagnosed IUGR & 3 & 2 \\
Sensitivity & $92.86 \%$ & $92.86 \%$ \\
Specificity & $50.0 \%$ & $66.67 \%$ \\
Positive predictive value (PPV) & $81.25 \%$ & $86.67 \%$ \\
Negative predictive value (NPV) & $75.00 \%$ & $80.00 \%$ \\
Accuracy & $80.00 \%$ & $85.00 \%$ \\
\hline
\end{tabular}

IUGR, intrauterine growth retardation.

picture quality improvement, equipment calibration, proper design, and refinement of measuring methods may help in reducing variability. More research is needed to improve the universal validity and accuracy of fetal weight estimate equations [45].

4.1. Limitation. The study considered only two formulas to estimate the EFWs by ultrasonographic measurements.

\section{Conclusion}

Both Shepard's and Hadlock's provide fair estimates of fetal weight with minimal error and may be considered valuable tools in predicting the weight of fetuses in pregnancies in this region.

\section{Data Availability}

The data used to support the findings of this study are included within the article.

\section{Disclosure}

This research was performed as part of Assam Medical College's employment.

\section{Conflicts of Interest}

The authors declare that they have no conflicts of interest.

\section{Acknowledgments}

The authors acknowledge the department's staff members who have helped them complete this work by providing the department's necessary infrastructures.

\section{References}

[1] S. Campbell, "A short history of sonography in obstetrics and gynaecology," Facts, Views \& Vision in ObGyn, vol. 5, no. 3, pp. 213-229, 2013.

[2] E. Ugwu, P. Udealor, B. Ozumba et al., "Accuracy of clinical and ultrasound estimation of fetal weight in predicting actual birth weight in Enugu, southeastern Nigeria," Nigerian Journal of Clinical Practice, vol. 17, no. 3, pp. 270-275, 2014.

[3] C. Njoku, C. Emechebe, P. Odusolu, S. Abeshi, C. Chukwu, and J. Ekabua, "Determination of accuracy of fetal weight using ultrasound and clinical fetal weight estimations in calabar south, south Nigeria," International Scholarly Research Notices, vol. 2014, Article ID 970973, 6 pages, 2014.

[4] J. Bajracharya, N. S. Shrestha, and C. Karki, "Accuracy of prediction of birth weight by fetal ultrasound," Kathmandu University Medical Journal, vol. 10, no. 38, pp. 74-76, 2012.

[5] R. M. Patterson, T. J. Prihoda, C. E. Gibbs, and R. C. Wood, "Analysis of birth weight percentile as a predictor of perinatal outcome," Obstetrics \& Gynecology, vol. 68, no. 4, pp. 459463, 1986.

[6] E. M. Ray and J. L. Alhusen, "The suspected macrosomic fetus at term: a clinical dilemma," Journal of Midwifery \& Women's Health, vol. 61, no. 2, pp. 263-269, 2016. 
[7] A. P. Frick, A. Syngelaki, M. Zheng, L. C. Poon, and K. H. Nicolaides, "Prediction of large-for-gestational-age neonates: screening by maternal factors and biomarkers in the three trimesters of pregnancy," Ultrasound in Obstetrics and Gynecology, vol. 47, no. 3, pp. 332-339, 2016.

[8] A. R. Bjørstad, K. Irgens-Hansen, A. K. Daltveit, and L. M. Irgens, "Macrosomia: mode of delivery and pregnancy outcome," Acta Obstetricia et Gynecologica Scandinavica, vol. 89, no. 5, pp. 664-669, 2010.

[9] J. R. King, L. M. Korst, D. A. Miller, and J. G. Ouzounian, "Increased composite maternal and neonatal morbidity associated with ultrasonographically suspected fetal macrosomia," Journal of Maternal-Fetal and Neonatal Medicine, vol. 25, no. 10, pp. 1953-1959, 2012.

[10] N. S. Fox, V. Bhavsar, D. H. Saltzman, A. Rebarber, and S. T. Chasen, "Influence of maternal body mass index on the clinical estimation of fetal weight in term pregnancies," Obstetrics \& Gynecology, vol. 113, no. 3, pp. 641-645, 2009.

[11] J. Willocks, I. Donald, S. Campbell, and I. R. Dunsmore, "Intrauterine growth assessed by ultrasonic foetal cephalometry," BJOG: An International Journal of Obstetrics and Gynaecology, vol. 74, no. 5, pp. 639-647, 1967.

[12] S. Campbell and D. Wilkin, "Ultrasonic measurement of fetal abdomen circumference in the estimation of fetal weight," BJOG: An International Journal of Obstetrics and Gynaecology, vol. 82, no. 9, pp. 689-697, 1975.

[13] J. Higginbottom, J. Slater, G. Porter, and C. R. Whitfield, "Estimation of fetal weight from ultrasonic measurement of trunk circumference," BJOG: An International Journal of Obstetrics and Gynaecology, vol. 82, no. 9, pp. 698-701, 1975.

[14] S. L. Warsof, P. Gohari, R. L. Berkowitz, and J. C. Hobbins, "The estimation of fetal weight by computer-assisted analysis," American Journal of Obstetrics and Gynecology, vol. 128, no. 8, pp. 881-892, 1977.

[15] I. E. Timor-Tritsch, J. Itskovitz, and J. M. Brandes, "Estimation of fetal weight by real-time sonography," Obstetrics \& $G y$ necology, vol. 57, no. 5, pp. 653-656, 1981.

[16] M. J. Shepard, K. G. Hellenbrand, and M. B. Bracken, "Proportional weight gain and complications of pregnancy, labor, and delivery in healthy women of normal prepregnant stature," American Journal of Obstetrics and Gynecology, vol. 155, no. 5, pp. 947-954, 1986.

[17] F. P. Hadlock, R. B. Harrist, R. S. Sharman, R. L. Deter, and S. K. Park, "Estimation of fetal weight with the use of head, body, and femur measurements-a prospective study," American Journal of Obstetrics and Gynecology, vol. 151, no. 3, pp. 333-337, 1985.

[18] K. Kanakaraj, K. Mariappan, and S. Farid, "Estimation of foetal weight at term pregnancy by clinical and ultrasonographic methods," Scholars Academic Journal of Biosciences, vol. 5, no. 1, pp. 72-77, 2017.

[19] A. Fleming, J. D. Riva, and G. McAdoo, "Estimation of fetal weight by ultrasound in term pregnancy," Journal of Diagnostic Medical Sonography, vol. 12, no. 1, pp. 7-10, 1996.

[20] R. Bukowski, T. Uchida, G. C. S. Smith et al., "Individualized norms of optimal fetal growth," Obstetrics \& Gynecology, vol. 111, no. 5, pp. 1065-1076, 2008.

[21] S. N. Hinkle, P. S. Albert, P. Mendola et al., "The association between parity and birthweight in a longitudinal consecutive pregnancy cohort," Paediatric \& Perinatal Epidemiology, vol. 28, no. 2, pp. 106-115, 2014.

[22] A. Garces, W. Perez, M. S. Harrison, K. S. Hwang, T. L. Nolen, and R. L. Goldenberg, "Association of parity with birth weight and neonatal death in five sites: the global network's maternal newborn health registry study," Reproductive Health, vol. 17, no. 3, 2020.

[23] P. S. Shah, "Parity and low birth weight and preterm birth: a systematic review and meta-analyses," Acta Obstetricia et Gynecologica Scandinavica, vol. 89, no. 7, pp. 862-875, 2010.

[24] S. Lumbanraja, D. Lutan, and I. Usman, "Maternal weight gain and correlation with birth weight infants," Procedia-Social and Behavioral Sciences, vol. 103, pp. 647-656, 2013.

[25] D. Zhang, L. Zhang, and Z. Wang, "The relationship between maternal weight gain in pregnancy and newborn weight," Women and Birth, vol. 32, no. 3, pp. 270-275, 2019.

[26] L. Liu, Y. Ma, N. Wang, W. Lin, Y. Liu, and D. Wen, "Maternal body mass index and risk of neonatal adverse outcomes in China: a systematic review and meta-analysis," $B M C$ Pregnancy and Childbirth, vol. 19, no. 1, pp. 1-12, 2019.

[27] S. Ashtekar, M. Kulkarni, V. Sadavarte, and R. Ashtekar, "Analysis of birth weights of a rural hospital," Indian Journal of Community Medicine, vol. 35, no. 2, pp. 252-255, 2010.

[28] C. S. Metgud, V. A. Naik, and M. D. Mallapur, "Factors affecting birth weight of a newborn - a community based study in rural Karnataka, India," PLoS One, vol. 7, no. 7, Article ID e40040, 2012.

[29] B. Hota and N. Movva, "Newborn birth weight in normal pregnancy in rural Telangana," Journal of Dr. NTR University of Health Sciences, vol. 6, no. 4, p. 232, 2017.

[30] R. Khadka, "Validation of Hadlock's and shepard formulae of fetal weight estimation in eastern region of Nepal," Birat Journal of Health Sciences, vol. 4, no. 2, pp. 738-743, 2019.

[31] E. Peregrine, P. O’Brien, and E. Jauniaux, "Clinical and ultrasound estimation of birth weight prior to induction of labor at term," Ultrasound in Obstetrics and Gynecology, vol. 29, no. 3, pp. 304-309, 2007.

[32] S. Q. Rashid, “Accuracy of sonographic fetal weight estimation in Bangladesh," Journal of Medical Ultrasound, vol. 23, no. 2, pp. 82-85, 2015.

[33] C. O. Okafor, C. I. Okafor, Mbachu II, I. C. Obionwu, and M. E. Aronu, "Correlation of ultrasonographic estimation of fetal weight with actual birth weight as seen in a private specialist hospital in south east Nigeria," International Journal of Reproductive Medicine, vol. 2019, Article ID 3693797 , 4 pages, 2019.

[34] S. C. Westerway, "Estimating fetal weight for best clinical outcome," Australasian Journal of Ultrasound in Medicine, vol. 15, no. 1, pp. 13-17, 2012.

[35] M. Hoopmann, K. Kagan, A. Sauter, H. Abele, and P. Wagner, "Comparison of errors of 35 weight estimation formulae in a standard collective," Geburtshilfe und Frauenheilkunde, vol. 76, no. 11, pp. 1172-1179, 2016.

[36] A. Ravooru, J. Gupta, and A. R. Anand, "Comparative study of effective fetal weight by clinical formula with USG Hadlock formula," International Journal of Clinical Obstetrics and Gynaecology, vol. 4, no. 4, pp. 147-151, 2020.

[37] B. Kanaka Durgaprasad, S. Sharma, G. Indira, A. Bishaik, and V. Suresh, "Comparative study between clinical methods and ultrasound examination in the estimation of fetal weight," International Journal of Health Sciences \& Research, vol. 9, no. 5, p. 79, 2019.

[38] J. Siemer, N. Egger, N. Hart et al., "Fetal weight estimation by ultrasound: comparison of 11 different formulae and examiners with differing skill levels," Ultraschall in der Medizin, vol. 29, no. 2, pp. 159-164, 2008.

[39] D. Kumara and H. Perera, "Evaluation of six commonly used formulae for sonographic estimation of fetal weight in a Sri 
Lankan population," Sri Lanka Journal of Obstetrics and Gynaecology, vol. 31, no. 1, p. 20, 2010.

[40] N. Waseem, R. Afsar, N. Batool, W. Aleem, and C. Author, "The ultrasound evaluation of fetal biometry in intrauterine growth restriction: a narrative review," Allied Health Sciences, vol. 6, no. 2, pp. 33-41, 2020.

[41] J. Gebb and P. E. Dar, "Colour Doppler ultrasound of spiral artery blood flow in the prediction of pre-eclampsia and intrauterine growth restriction," Best Practice \& Research Clinical Obstetrics \& Gynaecology, vol. 25, no. 3, pp. 355-366, 2011.

[42] B. S. Hennington and B. T. Alexander, "Linking intrauterine growth restriction and blood pressure," Circulation, vol. 128, no. 20, pp. 2179-2180, 2013.

[43] L. Zezza, E. Ralli, E. Conti, J. Passerini, C. Autore, and D. Caserta, "Hypertension in pregnancy: the most recent findings in pathophysiology, diagnosis and therapy," Minerva Ginecologica, vol. 66, no. 1, pp. 103-126, 2014.

[44] F. A. Manning, C. M. Hill, and L. D. Platt, "Qualitative amniotic fluid volume determination by ultrasound: antepartum detection of intrauterine growth retardation," American Journal of Obstetrics and Gynecology, vol. 139, no. 3, pp. 254-258, 1981.

[45] N. J. Dudley, "A systematic review of the ultrasound estimation of fetal weight," Ultrasound in Obstetrics and Gynecology, vol. 25, no. 1, pp. 80-89, 2005. 